\title{
Diagnostic efficacy of double-balloon enteroscopy in patients with suspected isolated small bowel Crohn's disease
}

\author{
Zihan Huang, Xiang Liu, Fei Yang, Guoxin Wang, Nan Ge, Sheng Wang, Jintao Guo and Siyu Sun
}

\begin{abstract}
Background: Owing to the development of double-balloon enteroscopy (DBE) and video capsule endoscopy (VCE) in recent years, direct visualization of the entire small intestinal mucosa has become possible. Because of the nonspecific symptoms and the anatomic location of the small bowel, diagnosis of isolated small bowel Crohn's disease (CD) remains a challenge. The aim of this research was to explore the value of DBE for isolated small bowel $C D$ in situations where routine tests cannot confirm the diagnosis.

Methods: This study included patients with suspected isolated small bowel CD who were hospitalized in Shengjing Hospital from April 2014 to June 2018. We included patients presenting with chronic diarrhea, abdominal pain, abdominal mass, perianal lesions, and systemic symptoms including weight loss, fever, and anemia after excluding infection factors. Patients with purely colonic CD were excluded from this cohort. Patients with suspected isolated small bowel CD underwent DBE.

Results: In 16/18 patients, pathological findings were detected by DBE. In 12 of the cases, small bowel CD was confirmed. The remaining four patients were diagnosed with small bowel inflammation, duodenal carcinoma, ileum inflammation and small bowel ulcers. However, the diagnosis of CD was confirmed in 14/18 (78\%) patients by taking into account the clinical presentation, endoscopic and histological results as well as the experimental treatment. DBE assisted in the diagnosis in $86 \%(12 / 14)$ of the patients.

Conclusions: In the diagnosis of small bowel CD, DBE is a helpful tool. Before assessment with DBE, clinical features, colonoscopy, and $\mathrm{CT}$ were used to initially assess the intestine. According to the lesions indicated by $\mathrm{CT}$, we chose the most appropriate endoscope insertion route, and combined the endoscopic characteristics and pathological results of DBE to confirm the diagnosis.
\end{abstract}

Keywords: Double-balloon enteroscopy, Inflammatory bowel disease, Crohn's disease, Small bowel

\section{Background}

Crohn's disease $(\mathrm{CD})$ is an inflammatory disease that can involve the entire gastrointestinal tract. According to previous reports, in $30-70 \%$ of patients with $C D$, the small bowel is affected, and in up to $30 \%$ of patients diagnosed with $\mathrm{CD}$, only the small bowel is involved $[1,2]$. It is difficult to diagnose isolated small bowel $\mathrm{CD}$ because of the nonspecific symptoms and anatomic location of the small bowel. According to the location and pathological behavior (including the development of penetration and

\footnotetext{
*Correspondence: liux@sj-hospital.org; liux_2017@163.com

The Department of Gastroenterology, Shengjing Hospital, China Medical

University, No.36, Sanhao Street, Shenyang 110004, Liaoning Province, China
}

strictures), CD has different clinical manifestations. The pathological changes occurring in the distal part of the ileum manifest mainly as intestinal stenosis, which occurs as the disease progresses [3, 4]. Stenosis and penetration (perforation) are major complications and require surgical intervention. Some patients with a long medical history and recurrence of disease complain of obstructive symptoms in the first medical consultation, and many patients receive delayed diagnosis and treatment. Early identification and treatment of $\mathrm{CD}$ involving the small bowel may be beneficial to these patients.

As there is no gold standard for the diagnosis of CD, the defined diagnosis usually requires the combination

(C) The Author(s). 2020 Open Access This article is distributed under the terms of the Creative Commons Attribution 4.0 International License (http://creativecommons.org/licenses/by/4.0/), which permits unrestricted use, distribution, and 
of clinical, endoscopic, radiological, and histological features and the exclusion of an infectious etiology [5]. Traditionally, the tools for diagnosing CD have included esophagogastroduodenoscopy (EGD), colonoscopy, Xray tests, and high-resolution ultrasound. Computed tomography (CT) and magnetic resonance (MR) are traditionally used standards for examining the small intestine. CT and MR are accurate techniques for detecting extraluminal complications. The European consensus has proposed the use of MR enterography/enteric (MRE) and CT enterography/enteric (CTE) to detect intestinal involvement and penetrating lesions in CD. Both are considered imaging techniques with the highest diagnostic accuracy [6,7]. Video capsule endoscopy (VCE) and double-balloon enteroscopy (DBE) have become effective tools in diagnosing small bowel CD [8]. The advantage of DBE is not only direct visualization of the small bowel mucosa but it also allows for biopsy of the lesion and therapeutic interventions [9]. DBE can be used to diagnose unclear small bowel disease or suspected cancer and can also be used in rare cases in which tissue pathological examination is required. The aim of this research was to explore the value of DBE for the diagnosis of isolated small bowel CD.

\section{Methods}

This study was conducted in accordance with the Helsinki Declaration and was approved by the ethics committee of Shengjing Hospital of China Medical University. It was conducted at Shengjing Hospital from April 2014 to June 2018. DBE was performed on patients with clinically suspected small bowel CD. The patients' medical records were retrieved from the prospective hospital database and reviewed for general information, medical history, physical examination, laboratory tests, radiology, endoscopy and histology results. All patients signed a written informed consent to undergo DBE and were informed about the risks of the examination, including the biopsy procedure.

We included patients presenting with chronic diarrhea, abdominal pain, abdominal mass, perianal lesions, and systemic symptoms including weight loss, fever, and anemia after excluding infection factors. Preliminary laboratory tests included routine blood work, C-reactive protein (CRP), erythrocyte sedimentation rate (ESR), serum albumin, and fecal calprotectin. Patients underwent EGD, colonoscopy, CT and additional imaging modalities such as CTE or VCE. For patients with suspected obstruction, before VCE was preformed, it was necessary to confirm the disappearance of the obstruction according to the assessment of results by CT. After analyzing these abnormal findings, we performed DBE in patients with high suspicion of small bowel CD.
Patients with colonic lesions were excluded from this study.

All patients were fasted for at least $12 \mathrm{~h}$ and polyethylene glycol-based bowel preparation was administered before the procedure. DBE was performed in an endoscopic operating room with fluoroscopic function. Patients were administered conscious sedation with propofol (Lipuro ${ }^{\circ}$; Braun, Melsungen, Germany) by an anesthesiologist and then subjected to electrocardiographic monitoring. DBE was performed using Fujinon enteroscopes (Fujinon EN 450P 5/20, EN-450 T5; Fujinon Corp, Saitama, Japan). Carbon dioxide $\left(\mathrm{CO}_{2}\right)$ was pumped using a $\mathrm{CO}_{2}$ regulator (Olympus UCR; Olympus) connected to a $\mathrm{CO}_{2}$ gas cylinder during the procedure. The flow rate for $\mathrm{CO}_{2}$ insufflation was set at $1.0 \mathrm{~L} /$ minute in all patients. The TCM4 detector (Linde Medical Sensors, Basel, Switzerland) used a low-pressure clip connected sensor to measure $\mathrm{PtcCO}_{2}$ non-invasively and continuously. $\mathrm{PtCO}_{2}$ was measured just before the examination and after finishing the procedure. We used biopsy forceps to perform tissue acquisition of suspected lesions in different sites. At least two samples were taken from each site and five samples were taken at the site of obvious lesions.

\section{Results}

A total of 49 patients were diagnosed with small bowel $\mathrm{CD}$, of which 18 patients were difficult to confirm by conventional tests. 13 males and 5 females were included in this study and 21 DBEs were performed. The mean age of patients diagnosed with small bowel CD was 41.5 years. In seven patients, the insertion route was oral, in eight patients the insertion was through the anal route, and in three patients both oral and anal approaches were used. We estimated insertion depth on the basis of the number of strokes (insertion and withdrawal cycles). The average depth of insertion was $235 \pm 95 \mathrm{~cm}$ (oral route) and $77 \pm 40 \mathrm{~cm}$ (anal route). Clinical characteristics of the patients, endoscopic findings and CT results are summarized in Table 1.

The endoscopic features suggesting a diagnosis of $C D$ include aphthous ulcers, longitudinal ulcers, a cobblestone-like appearance, intestinal stenosis and segmental lesions, as shown in Fig. 1. Microscopic characteristics of $\mathrm{CD}$ in biopsy specimens are focal (discontinuous) chronic inflammation, focal crypt irregularity (discontinuous crypt distortion), and granulomas (not related to crypt injury). Aphthous ulcers, linear ulcers, deep fissures with knife-like clefts, and transmural lymphoid hyperplasia also suggest a CD diagnosis. The results of $\mathrm{DBE}$, histological findings and clinical diagnoses are summarized in Table 2.

As shown in Fig. 2, in 18 patients, 16 had abnormal lesions observed via DBE, and 12 were diagnosed with 


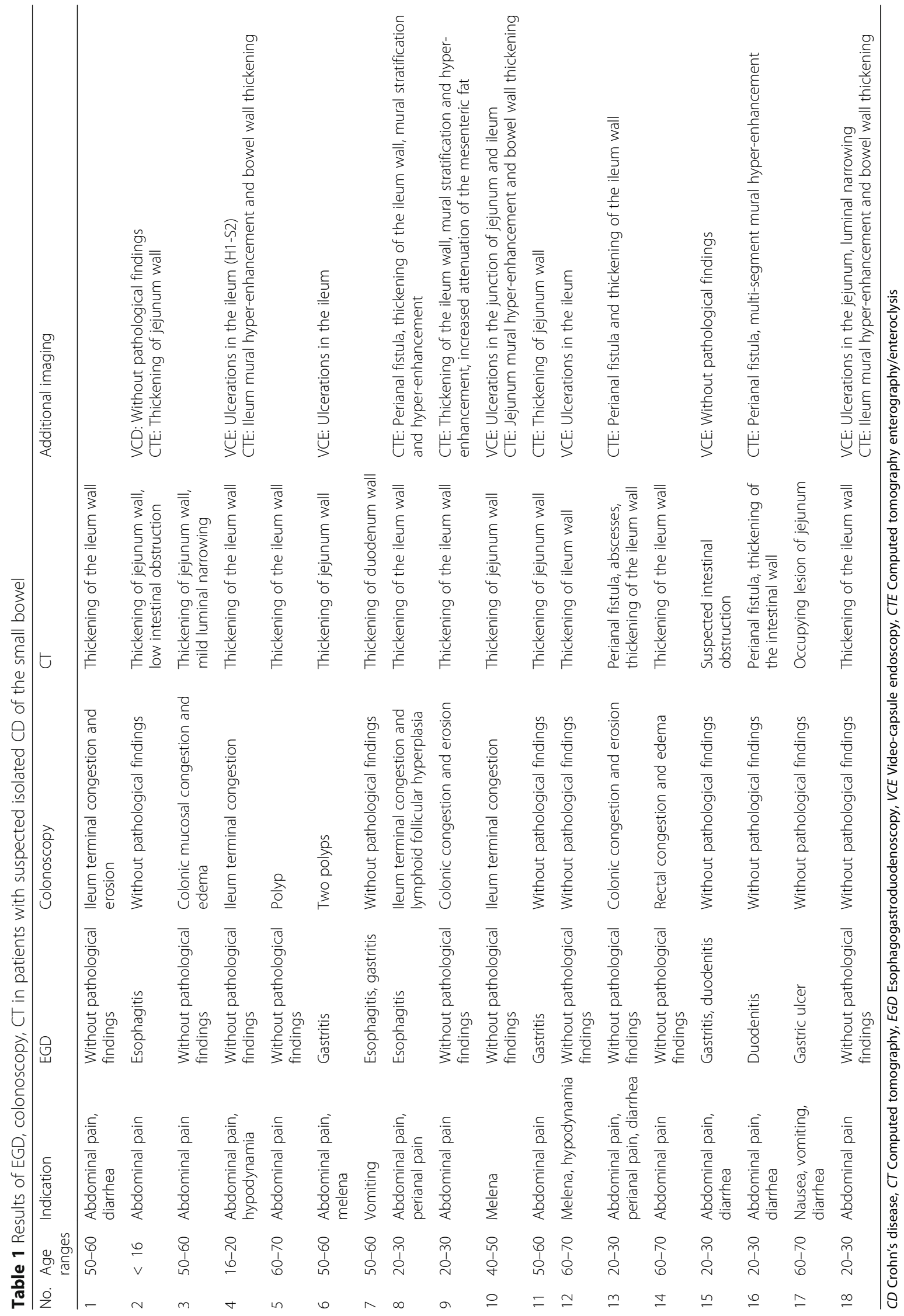




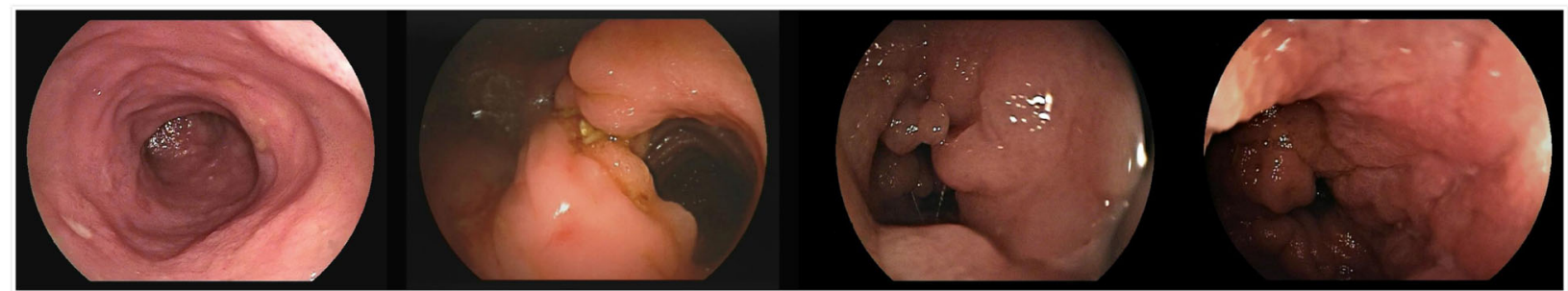

Fig. 1 Endoscopic performance of small bowel Crohn's disease under double balloon enteroscopy

small bowel CD after comprehensive analysis. Among the remaining four patients, one was diagnosed with small bowel inflammation, one was diagnosed with duodenal carcinoma, one was diagnosed with ileum inflammation, and one was diagnosed with small bowel ulcers. Of all patients enrolled, only two patients were

Table 2 Results of DBE and histological examination

\begin{tabular}{|c|c|c|c|c|c|}
\hline No. & $\begin{array}{l}\text { Insertion } \\
\text { route }\end{array}$ & $\begin{array}{l}\text { Insertion } \\
\text { depth }(\mathrm{cm})\end{array}$ & DBE & Biopsy & Clinical diagnosis \\
\hline 1 & Anal & 70 & $\begin{array}{l}\text { Mucosal edema, congestion and erosion, } \\
\text { multiple polypoid hyperplasia }\end{array}$ & Focal chronic inflammation, crypt regularity & lleum inflammation \\
\hline 2 & Oral & 330 & $\begin{array}{l}\text { Multiple longitudinal ulcers in jejunum and } \\
\text { ileum, cobblestone-like appearance }\end{array}$ & $\begin{array}{l}\text { Focal chronic inflammation, lymphoid } \\
\text { hyperplasia }\end{array}$ & $C D(A 1,\llcorner 4, B 2)$ \\
\hline $2^{\wedge}$ & Anal & 40 & Without pathological findings & No data & $C D(A 1, L 4, B 2)$ \\
\hline 3 & Oral & 300 & $\begin{array}{l}\text { Intestinal stenosis, segmental ulcers in the } \\
\text { junction of jejunum and ileum }\end{array}$ & Focal inflammation, ulcerative lesions & $C D(A 3,\llcorner 4, B 2)$ \\
\hline 4 & Anal & 40 & $\begin{array}{l}\text { Multiple aphthous ulcers and longitudinal } \\
\text { ulcers }\end{array}$ & $\begin{array}{l}\text { Focal chronic inflammation, crypt irregularity } \\
\text { and lymphoid hyperplasia }\end{array}$ & $\mathrm{CD}(\mathrm{A} 2, \mathrm{~L} 1, \mathrm{~B} 1)$ \\
\hline 5 & Oral & 160 & Without pathological findings & No data & $C D(A 3,\llcorner 4, B 1)$ \\
\hline 6 & Oral & 350 & Multiple aphthous ulcers in jejunum & Ulcerative lesions, mild dysplasia & Small bowel ulcers \\
\hline 7 & Oral & 20 & Intestinal stenosis, longitudinal ulcers & Focal high-grade intraepithelial neoplasia & Duodenal carcinoma \\
\hline 8 & Anal & 30 & Multiple longitudinal ulcers in ileum & $\begin{array}{l}\text { Granulomas, acute inflammation and focal } \\
\text { crypt irregularity }\end{array}$ & $C D(A 2, L 1+L 4, B 1 p)$ \\
\hline 9 & Anal & 75 & Intestinal stenosis, longitudinal ulcers in ileum & $\begin{array}{l}\text { Focal chronic inflammation, lymphoid } \\
\text { hyperplasia }\end{array}$ & $C D(A 2,\llcorner 4, B 2)$ \\
\hline 10 & Oral & 240 & Without pathological findings & No data & $C D(A 3, L 1+L 4, B 1)$ \\
\hline 11 & Oral & 240 & Mucosal congestion and erosion & No data & $\begin{array}{l}\text { Small bowel } \\
\text { inflammation }\end{array}$ \\
\hline 12 & Anal & 30 & Aphthous ulcers, mucosal congestion & $\begin{array}{l}\text { Focal acute and chronic inflammation, } \\
\text { lymphoid hyperplasia }\end{array}$ & $C D(A 3,\llcorner 4, B 1)$ \\
\hline 13 & Anal & 85 & $\begin{array}{l}\text { Segmental lesions of longitudinal ulcers in } \\
\text { ileum, cobblestone-like appearance }\end{array}$ & $\begin{array}{l}\text { Focal chronic inflammation, focal crypt } \\
\text { irregularity }\end{array}$ & $C D(A 2, L 1+L 4, B 1 p)$ \\
\hline 14 & Anal & 90 & $\begin{array}{l}\text { Multiple ulcers and ulcer scars in ileum, } \\
\text { polypoid hyperplasia }\end{array}$ & Focal acute and chronic inflammation & $\mathrm{CD}(\mathrm{A} 3, \mathrm{~L} 4, \mathrm{~B} 1)$ \\
\hline 15 & Anal & 140 & $\begin{array}{l}\text { Segmental lesions of longitudinal ulcers in } \\
\text { ileum }\end{array}$ & $\begin{array}{l}\text { Adenomatous hyperplasia with lymphoid } \\
\text { hyperplasia }\end{array}$ & $C D(A 2, L 4, B 2)$ \\
\hline 16 & Anal & 140 & Aphthous ulcers & No data & $C D(A 2, L 4, B 2 p)$ \\
\hline $16 \wedge$ & Oral & 270 & $\begin{array}{l}\text { Intestinal stenosis, longitudinal ulcers in } \\
\text { jejunum }\end{array}$ & $\begin{array}{l}\text { Ulcer with mild atypical hyperplasia, focal } \\
\text { acute and chronic inflammation }\end{array}$ & $C D(A 2, L 4, B 2 p)$ \\
\hline 17 & Oral & 190 & $\begin{array}{l}\text { Intestinal stenosis, multiple longitudinal ulcers } \\
\text { in jejunum }\end{array}$ & $\begin{array}{l}\text { Focal acute and chronic inflammation, focal } \\
\text { crypt irregularity }\end{array}$ & $C D(A 3,\llcorner 4, B 2)$ \\
\hline 18 & Anal & 110 & Without pathological findings & No data & $C D(A 2,\llcorner 4, B 2)$ \\
\hline $18 \wedge$ & Oral & 250 & Intestinal stenosis, segmental ulcers & $\begin{array}{l}\text { Focal inflammation, crypt irregularity and } \\
\text { transmural lymphoid hyperplasia, }\end{array}$ & $C D(A 2,\llcorner 4, B 2)$ \\
\hline
\end{tabular}




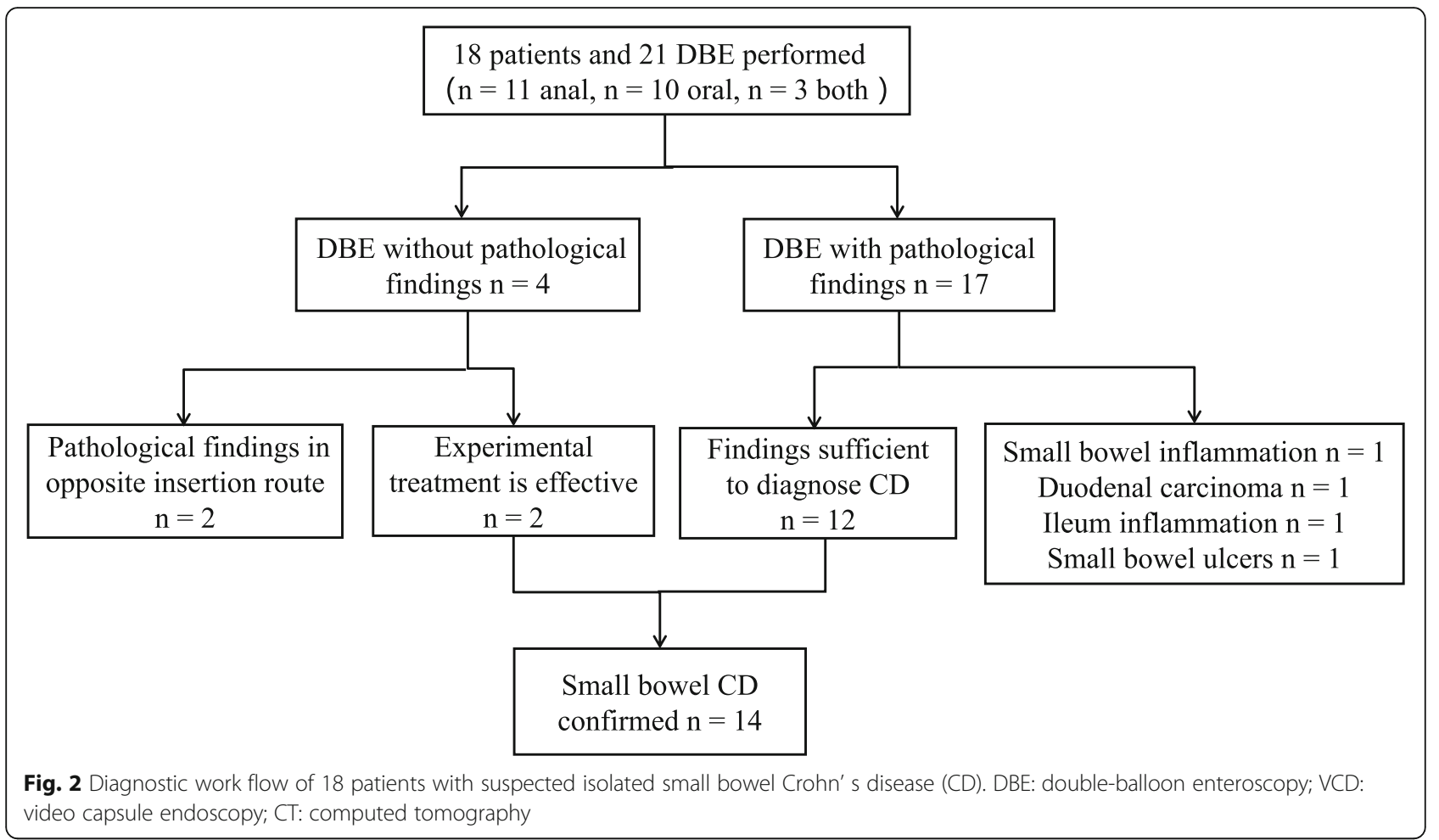

observed to have no abnormal lesions via DBE, but were later clinically confirmed to have small bowel $C D$ after experimental treatment. The principle of DBE operation is to insert the scope into the deep small bowel as much as possible. In one patient, DBE terminated in the middle of the jejunum, with an insertion depth of $240 \mathrm{~cm}$, and the patient's VCE showed multiple ulcerative lesions in the lower part of the jejunum and the upper part of the ileum. In another patient, DBE reached the upper part of the jejunum, with a depth of $160 \mathrm{~cm}$ through the oral side, until further insertion was not possible.

After the DBE results were combined with the clinical presentation of patients and imaging findings and experimental treatment, a diagnosis of $\mathrm{CD}$ was confirmed in 14 patients (78\%). DBE assisted in diagnosis in $86 \%$ $(12 / 14)$ of the patients.

\section{Discussion}

Owing to the characteristics of the small bowel anatomy, a sensitive and specific tool for the diagnosis of small bowel disease has been lacking. In our study, we found that DBE was useful to diagnose or confirm small bowel $\mathrm{CD}$ in patients after exclusion of abnormal changes in the upper gastrointestinal tract and colon. The absence of a gold standard for diagnosis also makes confirming small bowel CD difficult. For diagnosis of small bowel $\mathrm{CD}$, many new techniques can be used to identify small bowel lesions $[6,10]$. Recent studies have shown that the imaging techniques MRE and CTE have high sensitivity and specificity for recognizing active inflammation in the small bowel, especially for identifying stenosis, penetration, and extra-intestinal manifestations. On CTE, enteric findings such as mural hyper-enhancement, bowel wall thickening, mural stratification, engorged vasa recta ("comb sign"), and increased attenuation of the mesenteric fat are features of active inflammatory small bowel CD. According to the literature, the most common manifestation of CTE in established CD patients is thickening of the intestinal wall, up to at least $80 \%$ [11], in agreement with our results. Although this feature is not characteristic, the abnormalities in CTE should be different from those in cryptogenic multifocal ulcerous stenosing enteritis, intestinal involvement of diffuse connective tissue disease, and chronic ischemic bowel disease. CTE can indicate the location and extent of the lesion, providing clues to direct the insertion direction of DBE. Their noninvasiveness makes CTE and MRE acceptable and feasible in clinical practice $[7,12]$.

VCE is a noninvasive method with high sensitivity for detecting small bowel lesions. It can enable visualization of mucosal lesions, particularly superficial lesions [13, 14]. Lesions detected by VCE are nonspecific, and $C D$ cannot be distinguished from lesions caused by nonsteroidal anti-inflammatory drugs (NSAIDs) or other etiologies, on the basis of endoscopic images [15]. The randomness of the image capture in VCE results in high negative predictive value and lower specificity [16]. Positive consequences must be further identified and 
confirmed. Failure to obtain tissue for pathological results and the potential risk of capsule retention are major disadvantages of VCE. DBE is superior to radiology for detecting superficial lesions such as aphthous ulcers and erosions. Compared with VCE, it can accurately describe the location and morphology of lesions and surrounding mucosa (such as the appearance of pebbles and edema), thus helping to distinguish $\mathrm{CD}$ from other diseases $[17,18]$.

DBE is a helpful method when no abnormalities are observed using radiology and VCE but small bowel CD is suspected. Since the development of DBE in 2001 by Yamamoto et al. [9], its diagnostic ability in small bowel diseases has been extensively studied. It allows for direct visualization of the small bowel mucosa and has a broader and clearer field of vision than VCE [19]. CD is characterized by chronic granulomatous intestinal inflammation, and the lesions tend to be segmental and discontinuous. Multifocal lesions may have areas of different activity, and acute inflammatory and fibrotic strictures may be present at the same time. DBE can be used to visualize large portions of the small bowel, alone or in combination, and to examine small bowel inflammatory lesions [20]. The earliest and most characteristic endoscopic finding in small bowel CD is aphthous ulcers, which enlarge and deepen as the disease progresses, thus forming longitudinal ulcers. CD inflammation is often discontinuous, bordering on normal tissue, thereby resulting in segmental lesions. A cobblestone-like appearance occurs when longitudinal ulcers pass through areas of normal or inflamed tissue [5]. Other common endoscopic findings are thickening of the intestinal wall, varying degrees of stenosis, and cluster-like polyposis. The morphological features detected by DBE play a crucial role in the diagnosis of CD. A longitudinal ulcer along the mesenteric side is a typical morphological feature that can help to distinguish CD from other diseases that cause intestinal inflammation [21]. Ulcers associated with ischemia, intestinal tuberculosis, and Behcet's disease are common on the anti-mesenteric side of the bowel, whereas NSAID-associated ulcers have no such tendency in the intestinal lumen. The combination of typical macroscopic features with clinical manifestation, laboratory tests, smoking status, and family history may be sufficient to diagnose $\mathrm{CD}$.

Ideally, DBE can provide pathological support for the diagnosis of small bowel CD [22, 23]. The histology usually detected in patients with established $\mathrm{CD}$ includes focal (discontinuous) chronic inflammation, focal crypt irregularities, and granulomas [6]. Non-caseous granulomas are generally recognized as the most important microscopic features detectable for the diagnosis of CD. Non-caseous granuloma and at least one other microscopic feature (focal chronic inflammation or focal crypt irregularity) can be considered for $\mathrm{CD}$ [24]. In a retrospective study [22], despite positive macroscopic findings from DBE, $58 \%$ of the patients had normal or nonspecific histology, and $45 \%$ of patients were treated as having $\mathrm{CD}$ on the basis of a combination of histology, endoscopic appearance, clinical symptoms and laboratory tests. Although the discontinuity of inflammation and the superficiality of the biopsy tissue results in a lower chance of obtaining a granuloma under endoscopy, $10-30 \%$ of histological findings can still provide evidence to establish a diagnosis [25]. Clinical diagnosis requires pathological support to confirm the diagnosis of small bowel $C D$ and to help differentiate it from intestinal tuberculosis, Behcet's disease, lymphoma, and other diseases. Small bowel CD can be diagnosed using the six diagnostic points proposed by the WHO [24]. The diagnosis of small bowel CD involves clinical, endoscopic, radiological, and histological features; however, satisfying all the criteria may be impossible or unnecessary in practice. DBE should be considered complementary to other diagnosis methods. In ambiguous cases, the "test of time" is useful for CD diagnosis. Recurrent complaints, responses to therapy, and recurrent symptoms after stopping therapy may eventually verify the diagnosis.

When DBE presents as only superficial ulcers and mucosal inflammation in the small bowel, patients cannot be sufficiently diagnosed with $\mathrm{CD}$. Studies have reported that using endoscopic ultrasound (EUS) with DBE is more helpful in diagnosing inflammatory bowel disease because it shows the hierarchical structure of the intestinal wall of the small bowel $[26,27]$. Very few studies have reported the application of EUS with DBE in the small bowel, but EUS has been widely used in the diagnosis of digestive tract disease [28-31]. In addition to aiding in the diagnosis of small bowel CD, DBE can be useful in the provision of therapeutic interventions. Retrieval of retained VCE devices has been reported in several studies $[8,32]$. Owing to the recurrent nature of the disease, patients are prone to intestinal stenosis, and many patients will require multiple surgeries during the disease course. Surgical removal of the stenosis is a recognized solution, and half of patients require surgery within the first decade of diagnosis. A meta-analysis [33] has reported that small bowel clinical recurrence occurs in approximately $28 \%$ of patients after total colectomy with permanent ileostomy for colonic $\mathrm{CD}$. Endoscopic balloon dilation (EBD) is a safe and effective method that can replace small bowel resection in some cases [34].

In our study, no adverse events occurred (e.g., bleeding, perforation, pancreatitis and sedative-related adverse events) after DBE. According to different reports, the incidence of DBE complications is between $1.2 \%$ and $1.6 \%$ 
$[35,36]$. When the small bowel is contorted, or stenosis is present, any further insertion of the endoscope would increase the risk of perforation. For this reason, we stopped insertion in such situations. Determination of the most appropriate DBE insertion route is based on lesion location information provided by CT or other additional examinations. For the seven patients who underwent VCE, their insertion route was based mainly on the results of VCE. When the VCE and CT results were very different or without clear evidence of small bowel involvement, we chose the oral route for insertion because deeper insertion can be achieved via the oral route, increasing the potential of finding the lesions [37]. According to Mays' method [38], which is widely used in clinical practice and has been found to be effective in estimating the depth of endoscopic insertion, we estimated insertion depth by calculating the number of strokes (insertion and withdrawal cycles).

There are several limitations in this study that must be discussed. First, the study was a retrospective study with a small sample of patients. Because of the low incidence and low prevalence of small bowel CD in Asian regions, in this single center study, we were unable to obtain a larger sample, which may have affected diagnostic accuracy. Second, because skilled endoscopists and anesthesiologists are required, the application of DBE in the diagnosis of small bowel $C D$ is currently not widely used. Because our hospital is a tertiary referral center, our patients may not be representative of patients with small bowel CD. Many of the patients in this study had a relatively long medical history, and their condition was quite serious; thus, these patients may have had typical and obvious macroscopic features, enabling easier detection of lesions via DBE. On the one hand, this may have increased the diagnostic accuracy of DBE; on the other hand, opportunities to identify lesions may have been missed because of complicated abdominal conditions that limited the use of DBE, such as surgical adhesion and deep ulcers or stenosis of the bowel.

\section{Conclusions}

In patients with suspected small bowel CD, we recommend the use of DBE for the comprehensive evaluation of the gastrointestinal tract, thus contributing to clinical diagnosis in cases of negative EGD and colonoscopy. DBE is suitable when VCE or radiological examination reveals abnormal lesions, or when the results of these two methods are negative but small bowel CD is highly suspected. In the future, more indications using DBE will be developed to diagnose, monitor and treat small bowel CD.

\section{Abbreviations}

enteroclysis; DBE: Double-balloon enteroscopy; EBD: Endoscopic balloon dilation; EGD: Esophagogastroduodenoscopy; ESR: Erythrocyte sedimentation rate; EUS: Endoscopic ultrasound; MRE: Magnetic resonance enterography/ enteroclysis; NSAIDs: Nonsteroidal anti-inflammatory drugs; VCE: Video capsule endoscopy

\section{Acknowledgements}

Not applicable.

\section{Authors' contributions}

ZH was a major contributor in writing the manuscript. FY collected and analyzed the data. GW, NG, SW and JG preformed double balloon enteroscopy and analyzed the endoscopic images. XL and SS guided and reviewed the manuscript. All authors read and approved the final manuscript

\section{Funding}

This study was supported by the Shenyang Science and Technology Bureau (NO: F16-206-9-38)

\section{Availability of data and materials}

The datasets used and/or analysed during the current study available from the corresponding author on reasonable request.

\section{Ethics approval and consent to participate}

This study was approved by the ethics committee of Shengjing Hospital of China Medical University. All patients signed a written informed consent to undergo DBE and were informed about the risks of the examination, including the biopsy procedure. Patients under the age of 16 in this study received parental consent in written format.

\section{Consent for publication}

Not applicable.

\section{Competing interests}

The authors declare that they have no competing interests.

Received: 22 June 2019 Accepted: 11 February 2020

Published online: 26 February 2020

\section{References}

1. Satsangi J, Silverberg MS, Vermeire S, Colombel JF. The Montreal classification of inflammatory bowel disease: controversies, consensus, and implications. Gut. 2006;55:749-53.

2. Hall B, Holleran G, McNamara D. Small bowel Crohn's disease: an emerging disease phenotype? Dig Dis. 2015;33:42-51.

3. Louis E, Michel V, Hugot JP, et al. Early development of stricturing or penetrating pattern in Crohn's disease is influenced by disease location, number of flares, and smoking but not by NOD2/CARD15 genotype. Gut. 2003;52:552-7.

4. Oostenbrug LE, van Dullemen HM, te Meerman GJ, et al. Clinical outcome of Crohn's disease according to the Vienna classification: disease location is a useful predictor of disease course. Eur J Gastroenterol Hepatol. 2006;18: 255-61.

5. Wei SC, Chang TA, Chao TH, Chen JS, Chou JW, Chou YH, Chuang CH, Hsu WH, Huang TY, Hsu TC, et al. Management of Crohn's disease in Taiwan: consensus guideline of the Taiwan Society of Inflammatory Bowel Disease. Intest Res. 2017:15(3):285-310.

6. Van Assche G, Dignass A, Panes J, Beaugerie L, Karagiannis J, Allez M, Ochsenkühn T, Orchard T, Rogler G, Louis E, et al. The second European evidence-based consensus on the diagnosis and management of Crohn's disease: definitions and diagnosis. J Crohn's Colitis. 2010;4(1):7-27.

7. Bruining DH, Bhatnagar G, Rimola J, Taylor S, Zimmermann EM, Fletcher JG. $\mathrm{CT}$ and MR enterography in Crohn's disease: current and future applications. Abdom Imaging. 2015:40(5):965-74

8. Yen H-H, Chang C-W, Chou J-W, Wei S-C. Balloon-assisted enteroscopy and capsule endoscopy in suspected small bowel Crohn's disease. Clin Endosc. 2017:50:417-23.

9. Yamamoto $H$, Sekine $Y$, Sato $Y$, et al. Total enteroscopy with a nonsurgical steerable double-balloon method. Gastrointest Endosc. 2001;53:216-20. 
10. Markova I, Kluchova K, Zboril R, Mashlan M, Herman M. Small bowel imaging- still a radiologic approach? Biomed Pap MedFac Univ Palacky Olomouc Czech Repub. 2010;154:123-32.

11. Park MJ, Lim JS. Computed tomography enterography for evaluation of inflammatory bowel disease. Clin Endosc. 2013;46(4):327-66.

12. Lo Re G, Tudisca C, et al. CT enterography as a powerful tool for the CDAl and acute-phase reactants. Radiol Med. 2014;9:658-66.

13. Liao Z, Gao R, Xu C, et al. Indications and detection, completion, and retention rates of small-bowel capsule endoscopy: a systematic review. Gastrointest Endosc. 2010;71:280-6.

14. Goenka MK, Majumder S, Goenka U. Capsule endoscopy: present status and future expectation. World J Gastroenterol. 2014;20:10024-37.

15. Saibeni $S$, Emanuele R, lozzelli $A$, et al. Imaging of the small bowel in Crohn's disease: a review of old and new techniques. World J Gastroenterol. 2007;13:3279-87.

16. Chong AK, Taylor A, Miller A, Hennessy O, Connell W, Desmond P. Capsule endoscopy vs. push enteroscopy and enteroclysis in suspected small-bowel Crohn's disease. Gastrointest Endosc. 2005;61:255-61.

17. Wang J, Guo Q, Zhao J, Liu M, Liao G, Chen N, Tian D, Wu X. Multidetector CT enterography versus double-balloon enteroscopy: comparison of the diagnostic value for patients with suspected small bowel diseases. Gastroenterol Res Pract. 2016;2016:5172873.

18. Oshitani N, Yukawa T, Yamagami H, et al. Evaluation of deep small bowel involvement by double-balloon enteroscopy in Crohn's disease. Am J Gastroenterol. 2006;101:1484-9.

19. Cooley MD, Walker AJ, Gopal DV. From capsule endoscopy to balloonassisted deep enteroscopy: exploring small-bowel endoscopic imaging. Gastroenterol Hepatol. 2015;11(3):143-54.

20. Rondonotti E, Spada C, Adler S, et al. Small-bowel capsule endoscopy and device-assited enteroscopy for diagnosis and treatment of small-bowel disorders: European Society of Gastrointestinal Endoscopy (ESGE) technical review. Endoscopy. 2018;50(4):423-45.

21. Sunada $K$, Yamamoto $H$, Hayashi $Y$, Sugano $K$. Clinical importance of the location of lesions with regard to mesenteric or antimesenteric side of the small intestine. Gastrointest Endosc. 2007;66:534-8.

22. Tun GSZ, Rattehalli D, Sanders DS, McAlindon ME, Drew K, Sidhu R. Clinical utility of double-balloon enteroscopy in suspected Crohn's disease. Eur J Gastroenterol Hepatol. 2016;28(7):820-5.

23. Bourreille A, Ignjatovic A, Aabakken L, Loftus E Jr, Eliakim R, Pennazio M, Bouhnik Y, Seidman E, Keuchel M, Albert J, et al. Role of small-bowel endoscopy in the management of patients with inflammatory bowel disease: an international OMED-ECCO consensus. Endoscopy. 2009;41(07): 618-37.

24. Guarner F, Khan AG, Garisch J, et al. World gastroenterology organisation practice guideline: probiotics and prebiotics. Arab J Gastroenterol. 2009; 10(1):33-42.

25. Yantiss RK, Odze RD. Diagnostic difficulties in inflammatory bowel disease pathology. Histopathology. 2006:48(2):116-32.

26. Fukumoto A, Manabe N, Tanaka S, et al. Usefulness of EUS with doubleballoon enteroseopy for diagnosis of small-bowel diseases. Gastrointest Endosc. 2007;65:412-20.

27. Uberoi AS, Bhutani MS. Has the role of EUS in rectal cancer staging changed in the last decade? Endoscopic ultrasound. 2018;7(6):366-70.

28. Yamamoto K, Itoi T, Tsuchiya T, Tanaka R, Tonozuka R, et al. EUS-guided antegrade metal stenting with hepaticoenterostomy using a dedicated plastic stent with a review of the literature (with video). Endosc Ultrasound. 2018;7(6):404-12.

29. De Cobelli F, Marra P, Diana P, et al. Therapeutic EUS: biliary drainage - the interventional radiologist's perspective. Endosc Ultrasound. 2017;6:S127-31.

30. Park TY, Seo DW, Kang HJ, Song TJ, Park DH. Feasibility and safety of EUSguided selective portal vein embolization with a coil and cyanoacrylate in a live porcine model. Endosc Ultrasound. 2018;7(6):389-94.

31. Laghi A, Zerunian M, Caruso D. How new technologies could impact on radiology diagnosis and assessment of pancreatic lesions: future perspectives. Endosc Ultrasound. 2018;7(5):310-3.

32. Sunada K, Yamamoto H, Yano T, Sugano K. Advances in the diagnosis and treatment of small bowel lesions with Crohn's disease using double-balloon endoscopy. Ther Adv Gastroenterol. 2009:2:357-66.

33. Fumery M, Dulai PS, Meirick $P$, et al. Systematic review with meta-analysis: recurrence of Crohn's disease after total colectomy with permanent ileostomy. Aliment Pharmacol Ther. 2017;45(3):381-90.
34. Lopes S, Rodrigues-Pinto E, Andrade P, et al. Endoscopic balloon dilation of crohn disease strictures safety efficacy and clinical impact. World J Gastroenterol. 2017;23:7397-406.

35. Mensink PB, Haringsma J, Kucharzik T, et al. Complications of double balloon enteroscopy: a multicenter survey. Endoscopy. 2007;39:613-5.

36. Möschler O, May AD, Müller MK, Ell C, DBE-Studiengruppe Deutschland, et al. Complications in double-balloonenteroscopy: results of the German DBE register. Z Gastroenterol. 2008;46:266-70.

37. Sanaka MR, Navaneethan U, Kosuru B, Yerneni H, Lopez R, Vargo JJ. Antegrade is more effective than retrograde enteroscopy for evaluation and management of suspected small-bowel disease. Clinic Gastroenterol Hepatol. 2012;10:910-6.

38. Sugano K, Marcon N. The first international workshop on double balloon endoscopy: a consensus meeting report. Gastrointest Endosc. 2007;66(3):S7S11.

\section{Publisher's Note}

Springer Nature remains neutral with regard to jurisdictional claims in published maps and institutional affiliations.

Ready to submit your research? Choose BMC and benefit from:

- fast, convenient online submission

- thorough peer review by experienced researchers in your field

- rapid publication on acceptance

- support for research data, including large and complex data types

- gold Open Access which fosters wider collaboration and increased citations

- maximum visibility for your research: over $100 \mathrm{M}$ website views per year

At BMC, research is always in progress.

Learn more biomedcentral.com/submissions 